\title{
Horizontal learning: Teachers as learners in continuing professional development
} Lela Vuković

\begin{abstract}
Introduction
In modern society, it is more than ever obvious that an era of change has imposed on teachers a necessity to nurture their continuing professional development. A knowledge society demands various new training approaches and new teacher profiles. It seems crucial that teachers should be trained and up to date regarding the latest developments in their professional fields, both through formal and non-formal ways of delivering education programmes. Hence, the traditional conception of a teacher's role is becoming a bit obsolete, and teachers seem to take on a learner's role in teachers' continuing competence development, or as it is often called today - continuing professional development (CPD). In this paper, a special focus will be given to horizontal learning as a useful concept for teachers' CPD and specifically to teachers' forums as an example of CPD. Different topics and ideas that are shared at teachers' forums and which at the same time represent various instructional strategies, methods and techniques as examples of good practice, will be discussed in the methodological part of this paper, through a case study analysis.
\end{abstract}

\section{Teachers' CPD within the educational paradigm shift}

For many years teachers have been considered professionals in the sense that they have a solid theoretical grounding, several years of practical experience within their professional area, and that they are the decisive au- 
thority to choose when and where and how to prepare their work, and teach their students (Knudsen et al., 2011). However, in recent decades a new educational paradigm shift has brought many changes to a teachers' role in the learning community. The authors in this field argue that the emphasis is on new forms of relationships within the learning community, e.g., relationships amongst teachers, colleagues, students and society (Giddens, 1994; Hargreaves, 1994). The authors claim that problems must be solved by creating new professionalism, in which cooperation rather than competition defines the modern teacher's role. Furthermore, it has been suggested that what is needed now, in the new educational paradigm, are the following principles for ,active teacher professionalism' which redefine previous practice - inclusive membership, public ethical code of practice, collaborative and collegial, activist orientation, flexible and progressive, responsive to change, self - regulating, policy active, inquiry-oriented and knowledge building (Sachs, 2003:16). According to the author, these principles refer to the necessity of teaching practice changing towards a more comprehensive and competency-based society. These principles of , active teacher professionalism' imply that new teacher profiles and training approaches within CPD are needed in new learning environments.

\section{Teachers as Learners: how teachers learn}

According to author Dave Meier (2000), and his The Accelerated Learning Handbook, there is a four-phase learning cycle which encompasses:

- preparation: arousing interest

- presentation: encountering the new knowledge or skills

- $\quad$ practice: integrating the new knowledge or skills

- performance: applying the new knowledge and skills

The author claims that unless all four phases of learning are present in one form or another, no real learning occurs. Learning actually deteriorates or stops completely when one of the four stages is not present (Meier, 2000).

Another example of the learning cycle is the well-known Kolb's Learning Cycle (1984), which shows that we learn from our experience of life, even on an everyday basis. According to the author, the process of learning follows a pattern or cycle consisting of four stages: 
- concrete experience: do something

- reflective observation: think about what you did

- abstract conceptualization: make generalizations

- active experimentation: bearing in mind your conclusions

Kumaravadivelu's KARDS model stands for a modular model for knowing, analyzing, recognizing, doing and seeing and refers to a language teacher's education as well as to the way of sharing knowledge and experience through teacher-to-teacher collaboration (Hashamdar \& Etela, 2017). For Kumaravadivelu 'knowing ' is a dynamic concept referring to the process of knowledge building through professional knowledge, procedural knowledge and personal knowledge. 'Analyzing 'is focused on the learner's needs, motivation and autonomy, while 'recognizing 'is based on the importance of recognizing a teacher's identity, beliefs and values which form a teaching self that a teacher brings to the classroom. 'Doing ' in KARDS model refers to the process of transition from a traditional teacher's language to a critical teacher's language and finally 'seeing ' refers to a teachers' ability to make the connection between conceptual knowledge and perceptual knowledge in a classroom (Hashamdar \& Etela, 2017).

With these three aforementioned models of learning, we wanted to emphasize the fact that although learning is about perceiving inputs from the outside, whether it be by reading, listening, observing, and gaining experience from one source or another in the outside world, it is at the same time a complex process that can be achieved by constant reflection and experimentation.

During the learning process, external input is transferred by a teacher, a book or experience through one of two different processes: a) a vertical approach, which represents the traditional situation of an individual (a teacher) who has more knowledge and passes it onto several individuals (students) who have less knowledge; or b) a horizontal approach, in which participants learn together and from one another, and where they can be viewed as experts themselves (Knudsen et al., 2011).

In essence, the horizontal approach seems to be the starting point for horizontal learning, as a useful concept for an effective and efficient framework for teachers' joint learning. Authors from this field claim that in order to be useful and successful, a horizontal learning approach must be based on an appropriate learning environment. In other words, there are pertinent phenomena which characterize a well-functioning learning envi- 
ronment, which in turn ensure horizontal learning while at the same time securing an excellent basis for changing and improving practice. These phenomena are: a) teacher collaboration - providing teachers with opportunities to work and learn together; b) shared power and authority - between teachers and administrators; c) egalitarianism among teachers - status, power and authority; d) variation, challenge, autonomy and choice for teachers in their work; e) organizational goals and feedback mechanisms; f) integration of work and learning; and g) accessibility of external sources of learning (Smylie, 1995:106).

To conclude, there are many reasons for choosing the horizontal approach, one of them being that it involves more experts in the learning process than the vertical approach. Furthermore, in the majority of cases, the learning process is so similar to the practice that it can be used directly. The various benefits of the horizontal approach are easily noticeable in students' educational achievements within their school learning environment as learning is closely linked to teachers' daily practice. Finally, within the horizontal approach, there are many opportunities for teachers to exchange good practice that is of direct relevance for classroom teaching and has lower costs (input) since it can be provided locally, regionally, using internal resources.

\section{Why horizontal learning?}

The concept of horizontal learning is a competence-based connection between theory and practice in the workplace, that is the school learning community. The types of horizontal learning must be carefully selected to be suitable for the learning purpose and must cover activities that will be strategically relevant for the school to spend its resources on. In this way, horizontal learning as an integral part of CPD makes a difference in teachers' competence development while simultaneously enhancing school practice. Furthermore, it is much more cost-effective compared to traditional courses and seminars organized by experts. In short, this type of teachers' competence development could rely on a school's capacities-through lectures, examples of good practice, demonstration lessons or the dissemination of new information using a school's resources and organizing activities such as horizontal learning, i.e., learning from each other (Knudsen et al., 2011).

In addition to well-known teachers' techniques of practice exchanging such as conferences, seminars or mentorships, in modern school prac- 
tice, teacher forums are becoming an effective and efficient instructional technique within the concept of horizontal learning. Teacher forums are a specific technique that allows teachers to share various examples of good practice, clarifies the incoherent points of a subject, arouses the interest of audience/colleague teachers and provides them with active engagement. Various types of continuing professional development could be covered at teacher forums such as a) themes, methods and contents teachers are interested in; b) examples of innovative practice that teachers can offer from their own work; and c) presentation of different theoretical and empirical research data on a relevant school learning community (Gunduz, 2016). As illustrated by the following output, there are many benefits to teacher forums: mutual learning and exchange of good practice is closely linked to teachers' daily practice; forums are hosted locally and based on internal resources; there are a lot of opportunities to exchange good practice and lessons learned, directly relevant for classroom teaching; and finally, teacher forums ensure various improvements in the work of schools, teaching quality, teaching resources and tools.

\section{Methodological framework}

In the methodological part of this paper, we will present relevant qualitative pedagogical research data to exemplify a variety of possible horizontal learning outcomes after teacher forums held at Pavle Savić Technical School in Novi Sad, Serbia during the last school year. The topics discussed at the teacher forums in the first semester were related to project method and project-based learning. Teacher trainers demonstrated the basic principles of project-based learning to their teacher colleagues.

According to the Buck Institute for Education, project-based learning is, ,a systematic teaching method that engages students in learning knowledge and skills through an extended inquiry process structured around complex, authentic questions and carefully designed products and tasks", (BIE, 2012). These postulates have been demonstrated at the teacher forums through project-based teaching lessons in different subjects. Qualitative pedagogical research was conducted at the end of the school year in the form of an open question/semi-structured interview while the research question was defined as follows: Are there any differences in the attitudes of students who apply project-based learning, in the perception of basic teaching variables and learning objectives, in comparison to the practice of them being taught through traditional teaching methods? In that respect, the research 
aim was defined through an analysis of outcomes, from the students' perspective, that teacher forums have on changing school climate especially in the teaching and learning domain. Secondary school students $(\mathrm{N}=60,35=\mathrm{fe}$ male, $25=$ male) were interviewed in order to check the outcomes and possible influences on teaching processes after their teachers implemented and shared new ideas, knowledge and methods acquired at teacher forums. In this case study, several examples of students' narratives will be presented and analyzed, which refer to project-based teaching and learning, as applied during lessons from different subjects, some of which were general level subjects (English, geography, history, chemistry, physics) while others were vocational subjects (chemical technology, environmental protection, food production technology). Some of the interview questions posed to the interviewees were as follows: Describe your role in the teaching process while learning through the project method of teaching; Describe your teacher's style while teaching according to the project-based method; Can you implement the knowledge, beliefs and values gained through the project method of teaching to your everyday life; and, How would you describe the main difference between project-based teaching and traditional teaching methods?

Content analysis usually refers to analyzing text, therefore, in this paper, we applied thematic deductive analysis when analyzing students' narratives. The deductive analysis was applied and the data were examined according to a previously formed framework, developing possible categories, patterns and themes. This is often called ,open coding' (Strauss and Corbin 1998:223) and for this research, we established five categories according to the teaching variables and learning objectives examined through the form of an open question/semi-structured interview. These five categories have been defined as follows: 1. Learner's role; 2 . Teacher's role \& teacher's style; 3. Interdisciplinary learning in the project-based approach; 4. Competency-based learning stimulated in the project-based approach; and 5. Key differences between traditional teaching approaches and the project-based method. The categories have been perceived as a possible learning and teaching field where a change to the previous teaching and learning practice can be observed and analyzed as it refers to and is reflected on the three aforementioned models of learning, Meier's, Kolb's and Kumaravadivelu's.

\section{Results}

Quality analysis of data/students' narratives has shown that students highly value and assess teaching and learning in project-based method, as per- 
tains to attendance, motivation and empowerment for learning and being taught according to that teaching strategy, compared to traditional teaching methods. A thematic deductive analysis illustrated numerous differences in the attitudes of students who apply project-based learning, in their perception of basic teaching variables and learning objectives, as opposed to students taught using traditional teaching methods. For illustration purposes, some of the students' answers will be presented according to the examined teaching variables and learning objectives.

\section{Learner's role}

Student 8: I am always highly motivated to take part in a project-based task because I know exactly what I am supposed to do. I like to be part of a team while doing a project, and it's not unusual for me to choose to be the „leader". In projects, you simply cannot choose to do any other thing because if you miss the chance to finish your task, or don't respect the deadlines, your group will lose.

\section{Teacher's role \& teacher's style}

Student 12: Teachers seem to be our „friends on the same task “ while we are doing project assignments in some subjects (e.g. English). I like working and learning this way because I am sure that I have the support of both the teacher and my classmates. I respect and, to be honest, enjoy sending and receiving emails from my teacher referring to my responsibilities, terms, and everything else related to the project we are working on at the time. Teachers are not as strict while we are preparing our projects.

Student 4: I really like learning and preparing projects, primarily because we are able to use extra materials from different sources such as the Internet, libraries, etc., (not only our student's book) while getting ready for our final PowerPoint presentation, or panel discussion on the project topic/ subject. I like to make a personal contribution to the starting idea in a project and I know that my teacher and my classmates will accept it. For some reason, when it comes to projects, all ideas and different creative approaches are welcome and students know that their work and diligence will be respected. 


\section{Interdisciplinary learning in a project-based approach}

Student 7: It seems that everything depends on the project topic that we are working on, but I am sure that we can always apply the various knowledge we have acquired from all the different subjects. For example, we have been preparing an English project on coming of age in Japan. In order to do our best, we connected various content, and our knowledge from different subjects such as geography, history and sociology, especially in the part which talked about Japanese cultural elements, heritage, habits and mythology.

\section{Competency-based learning stimulated in the project-based approach}

Student 25: We did a project assignment for technology production of raw materials for pharmaceutical products. What I found so interesting and important was that some of the plants we were studying were poisonous and my family used to have them at home. I was able to apply this new knowledge to my daily life and my actual surroundings.

Student 6: The project we did for physics, called Oscillation, actually illustrated how my guitar strings produce vibrations and showed how an old pendulum clock at my grandfather's cottage worked... It was very significant for me because it allowed me to explain these phenomena through the formulae we learned while doing the project. The only example I was able to give before we started the project was that of my childhood swing.

\section{Key differences between traditional teaching approaches and the project-based method}

Student 31: Whenever we do a project, it seems to me that teaching and learning become more interesting while at the same time helping us express our creativity without being pressured to fit into a 45-minute lesson, as is the case in traditional classes.

Student 28: It seems that all of us are equally involved in teaching and learning while doing projects because if we want to finish our project we have to work together. It fosters teamwork and somehow you feel more comfortable and sure that the job will be done properly.

\section{Reflection on student answers}

As far as the first category, a learner's role, is concerned, a dominant pattern appeared in the students' narratives of them being aware of the importance of constructing knowledge out of a new learning strategy, as well as 
the importance of being a member of a team and completing the assignments on time. The students' perspective, on doing project work, is in line with the three learning cycle models and our hypothesis regarding the altered teacher's and learner's role in a new paradigm shift. The same is true for the second examined category of teacher's role and teacher's style with a dominant pattern emerging regarding positive classroom management, and an atmosphere which is conducive to stimulating students' personal contribution in the joint assignment and a team. As for the third category of interdisciplinary learning in the project-based approach, a dominant pattern emerged in the students' narratives regarding the significance of applying a cross-curricular approach which enhances students' motivation, arouses their interest in the subject matter by encountering new knowledge or skills and then integrating and applying that knowledge into a new context. The third examined category also confirmed our hypothesis that, according to the students' perception, the project-based method was more likely to foster learning and teaching than traditional teaching methods. The same is true for the fourth examined category of competency-based learning stimulated in a project-based approach where the dominant pattern which emerged, according to the students' perception, was that these projects were connected to real life and that they built up their competences and skills. Finally, the fifth examined category which summed up the key differences between traditional teaching approaches and the project-based method confirmed our hypothesis that students favoured learning and teaching according to the project-based method, as opposed to traditional teaching methods, which was illustrated by their positive attitudes, values and preferences.

\section{Conclusion}

The aim of this paper was to set out the basic frameworks for horizontal learning and to exemplify how some of the variations of this shared learning concept could enhance teachers' CPD. What we primarily focused on was that teachers could be both teachers and learners in their learning environments and that they could learn together and from one another, rather than from an external expert, through the horizontal learning concept. Teacher forums have been presented as a specific technique that gives teachers the opportunity to share various examples of good practice. As a whole, there are many benefits to teacher forums, some of which are examples of an exchange of good practice, directly relevant for classroom teaching practice 
and shown through the pedagogical qualitative research into students' perception of a novel teaching practice. We believe that further pedagogical research, of teachers' perspectives and attitudes or a self-assessment of teacher forums and possible benefits or obstacles to the same, would inevitably lead to broadening the teaching and learning horizon through the application of the horizontal learning concept in educational processes.

\section{Literature}

Giddens, Anthony. Beyond left and right: The future of radical politics, Oxford: Polity Press, 1994.

Gunduz, Feryal. „Instructional Techniques“. In Instructional Process and Concept in Theory and Practice. Improving the Teaching Process, edited by Akdeniz Celal, 147-233. N.p.: Singapore: Sprinser, 2016.

Hargreaves, Andy. Changing teachers, changing times: teachers work and culture in the postmodern age, London: Continuum, 1994.

Hashamdar, Mohammad, and Etela, Parisa. „A review of language teacher educations for a global society: A modular models for knowing, analyzing, recognizing, doing and seeing. „Modern Journal of Language Teaching Methods 7, no. 7(2017): 281-284.

Knudsen, Hans Jorgen et al. „Horizontal learning: A promising strategy for teachers' continuing professional development.“ In Learning from „Learn“ Horizontal learning in a community of practice in south eastern Europe, edited by Nielsen Soren, 31-39. N.p.: Luxembourg: Publication Office of EU, 2011.

Kolb, David. Experiential learning: experience as the source of learning and development. Englewood Cliffs (N.Y.): Prentice Hall, 1984.

Meier, Dave. The Accelerated Learning Handbook. New York: McGraw-Hill, 2000.

Sachs, Judyth. The activist teaching profession. New York: Open University Press, 2003.

Smylie, Mark A. „Teacher learning in the workplace." In Professional Development in Education. New Paradigms and Practices, edited by Guskey Thomas R. and Huberman Michael, 92-113.N.p.: New York: Teachers College Press, 1995.

Strauss, Anselm and Juliet Corbin. Basics of Qualitative Research: Techniques and Procedures for developing Grounded Theory. 2d.ed.Thousand Oaks, CA: Sage,1998. 


\section{Sources}

Buck Institute for Education. „Project-based learning for the 21st century.“ Accessed December 12, 2018. http://www.bie.org/about/what is pbl. 